\title{
Identification and Antibacterial Evaluation of some Selected Jordanian Medicinal Plants
}

\author{
WAEL A. AL-ZEREINI ${ }^{1}$, FUAD AL-RIMAWI ${ }^{2 *}$, SALEH ABU-LAFI ${ }^{3}$, FADI ALAKHRAS ${ }^{4}$, \\ GHASSAB M. AL-MAZAIDEH ${ }^{5}$, HAYA J. AYYAL SALMAN ${ }^{1}$ \\ and RASHEED M.A.Q. JAMHOUR ${ }^{5}$
}

${ }^{1}$ Department of Biological Sciences, Faculty of Science, Mutah University, P.O. Box 7, Mutah 61710, Al-Karak, Jordan.

${ }^{2}$ Chemistry Department, Faculty of Science and Technology, Al-Quds University, P.O. Box 20002, Jerusalem, Palestine.

${ }^{3}$ Faculty of Pharmacy, Al-Quds University, P.O. Box 20002, Jerusalem, Palestine.

${ }^{4}$ Department of Chemistry, College of Science, Imam Abdulrahman Bin Faisal University,

Dammam 31441, Saudi Arabia.

${ }^{5}$ Department of Chemistry and Chemical Technology, Faculty of Science, Tafila Technical University,

P.O. Box 179, Tafila 66110, Jordan.

*Corresponding author E-mail: falrimawi@staff.alquds.edu

http://dx.doi.org/10.13005/ojc/340530

(Received: July 25, 2018; Accepted: August 11, 2018)

\section{ABSTRACT}

Dried aerial parts of three medicinal plants grown wild in Jordan, namely Ononis natrix L, Salvia spinosa L. and Salvia verbenace L, were extracted upon soaking with ethyl acetate by continuous shaking at room temperature for three days. The extracts were analyzed for their phenolic and flavonoids content by HPLC-PDA. The HPLC analysis of the plant extracts revealed the presence of flavonoids and phenolic compounds in the three plant extracts. The antibacterial activity of the crude extract was evaluated. The PDA wavelengths range was from 227-347 nm. Bioactivities were attributed mainly to the immense content of phenol-based compounds in plants.

Keywords: Ononis natrix L, Salvia spinosa L, Salvia verbenace L, HPLC, Antibacterial.

\section{INTRODUCTION}

Plants are still being used as integral part of the primary healthcare, in developing countries, though synthetic medicinal drugs are available worldwide. Due to the emergence of new resistant pathogens to the most known antibiotics and because of the side effects of used drugs, they are considered as valuable natural sources of biologically active and potentially safe metabolites ${ }^{1-2}$. Plants represent a source of wide variety of secondary metabolites that could be effective in pure form such as anticorrosion

This is an Open Access article licensed under a Creative Commons Attribution-Non Commercial-Share Alike 4.0 International License (https://creativecommons.org/licenses/by-nc-sa/4.0/), which permits unrestricted Non Commercial use, distribution and reproduction in any medium, provided the original work is properly cited. 
inhibitors ${ }^{3-4}$ or in a synergy and to have bioactivities in different biological systems ${ }^{5}$. In fact, medicinal plants have provided the modern medicine with numerous therapeutic agents such as aspirin, atropine, colchicine, morphine, taxol, digitoxin, and quinine ${ }^{6-7}$.

In Jordan, about 2500 plant species belonging to 700 genera were recorded of which 485 species from 99 different families are categorized as medicinal plants and are widely distributed all over the country ${ }^{8-9}$. However, usage of these plant without awareness of their effect or dose toxicity, impose drawback in their medicinal benefits. Therefore, several studies were carried out on Jordanian medicinal plants, mainly on their antimicrobial and antioxidant activities ${ }^{10-12}$, phytochemistry ${ }^{13-14}$ and ethnobotany ${ }^{15-17}$. Hence, the aims of this work are to analyze the chemical compositions and to evaluate the bioactivity of three selected Jordanian medicinal plants that are used as a folk medicine for various ailments Table 1.

Table 1: List of selected Jordanian medicinal plants and their usage

\begin{tabular}{llc}
\hline Scientific name & Traditional use/medical use & Reference \\
\hline $\begin{array}{l}\text { Ononis natrix L. } \\
\text { (Fabacae) }\end{array}$ & $\begin{array}{l}\text { Antioxidant, diuretic, antihypertensive, } \\
\text { anti-bacterial, antispasmodic, diabetes, } \\
\text { and renal disorder }\end{array}$ & 11,17 \\
$\begin{array}{l}\text { Salvia spinosa L. } \\
\text { (Lamiaceae) }\end{array}$ & $\begin{array}{l}\text { Anti-stomach disturbturbance, anti-inflammatory, } \\
\text { anti-tussive, anti-rheumatic, carminative and hypotensive } \\
\text { Salvia verbenace L. }\end{array}$ & 18 \\
(Lamiaceae) & Antimicrobial, anti-hypertensive, diuretic and anti-tumor & 18 \\
\hline
\end{tabular}

Bioactivities of these plants were attributed mainly to their immense content of phenol-based compounds ${ }^{19}$. Such compounds are large group of secondary metabolites formed by plants to shield themselves versus pathogens. They are synthesized mainly via the shikimic acid pathways in plants, and contain a broad diversity of defense-related compounds counting flavonoids and other components ${ }^{20}$. Phenol based-compounds have received extensive consideration due to their physiological function, including their antioxidant activities and free radical scavenging abilities, which improve its beneficial implications from human health ${ }^{21}$.

Flavonoids which are water soluble polyphenolic molecules having 15 carbon atoms are free radical scavengers. They are belonging to the polyphenol family. Flavonoids have the ability to avoid oxidative cell destruction; also these moieties express a great anticancer protection and have the ability to decrease the threat of cardiovascular diseases. As antioxidants, flavonoids from plants provide anti-inflammatory activity. Consequently, medicinal plants have been used for the treatment of diseases in herbal medicine ${ }^{22}$. Introduction

Plants are still being used as integral part of the primary healthcare, in developing countries, though synthetic medicinal drugs are available worldwide. Due to the emergence of new resistant pathogens to the most known antibiotics and because of the side effects of used drugs, they are considered as valuable natural sources of biologically active and potentially safe metabolites ${ }^{1-2}$. Plants represent a source of wide variety of secondary metabolites that could be effective in pure form such as anticorrosion inhibitors ${ }^{3-4}$ or in a synergy and to have bioactivities in different biological systems ${ }^{5}$. In fact, medicinal plants have provided the modern medicine with numerous therapeutic agents such as aspirin, atropine, colchicine, morphine, taxol, digitoxin, and quinine ${ }^{6-7}$.

In Jordan, about 2500 plant species belonging to 700 genera were recorded of which 485 species from 99 different families are categorized as medicinal plants and are widely distributed all over the country ${ }^{8-9}$. However, usage of these plant without awareness of their effect or dose toxicity, impose drawback in their medicinal benefits. Therefore, several studies were carried out on Jordanian medicinal plants, mainly on their antimicrobial and antioxidant activities ${ }^{10-12}$, phytochemistry ${ }^{13-14}$ and ethnobotany ${ }^{15-17}$. Hence, the aims of this work are to analyze the chemical compositions and to evaluate the bioactivity of three selected Jordanian medicinal plants that are used as a folk medicine for various ailments Table 1. 
Bioactivities of these plants were attributed mainly to their immense content of phenol-based compounds ${ }^{19}$. Such compounds are large group of secondary metabolites formed by plants to shield themselves versus pathogens. They are manufactured mainly via the shikimic acid pathways in plants, and contain a broad diversity of defense-related compounds counting flavonoids and other components ${ }^{20}$. Phenol based-compounds have received extensive consideration due to their physiological function, including their antioxidant activities and free radical scavenging abilities, which improve its beneficial implications from human health ${ }^{21}$.

Flavonoids which are water soluble polyphenolic molecules having 15 carbon atoms are free radical scavengers. They are belonging to the polyphenol family. Flavonoids have the ability to avoid oxidative cell destruction; also these moieties express a great anticancer protection and have the ability to decrease the threat of cardiovascular diseases. As antioxidants, flavonoids from plants provide anti- inflammatory activity. Conseque

Free radicals resulting from oxygen, nitrogen and sulfur moieties in the bio-natural system are extremely dynamic to interact with further compounds because of their unpaired electrons. These radicals are considered vital component of groups of moieties named reactive oxygen/nitrogen species (ROS-RNS), which are formed through cellular metabolism and practical activities and have significant functions in cell signaling, apoptosis, gene appearance and ion carrying ${ }^{20-23}$.

Free radicals can be easily neutralized by polyphenolic and flavonoids through accepting or giving electron(s) to remove the unpaired condition of the radical. These antioxidants may instantly interact with the interactive radicals and demolish them, whereas they may turn into other free radicals which are minimal active, longer-lived and little severe than those radicals have been neutralized. Free radical molecules can also be neutralized by further antioxidants or other mechanisms to vanish their radical condition ${ }^{22-23}$.

Literature reviews revealed that no study has been carried out to correlate between the antibacterial activities and HPLC-PDA analysis of these three plants. Therefore, this study was conducted to reveal their activity and to analyze their phenolic and flavonoid constituents by HPLC-PDA. This study constitutes a valuable addition to the available literature.

\section{MATERIALS AND METHODS}

\section{Plant materials collection and extraction}

Plant samples were collected from different localities in the southern part of Al-Karak governorate-Jordan. They were identified according to Al-Eisawi (1998) and taxonomically authenticated by Dr. Ferryal Al-khreisat, Biology DepartmentMutah University. They were collected on the basis of traditional practices by herbalists and healers.

Aerial parts were dried in shade until constant weight and pulverized. $100 \mathrm{~g}$ of powdered plant materials were soaked in $1 \mathrm{~L}$ of ethyl acetate with continuous shaking (150 rpm, Forma Orbital Shaker, Thermo electron cooperation, USA) at room temperature for three days. The filtrates were concentrated under vacuum at $45^{\circ} \mathrm{C}$ using rotary evaporator (Buchi R-215, Switzerland) and the resulting residue was dissolved in methanol to a final concentration of $0.1 \mathrm{~g} / \mathrm{ml}$.

\section{In vitro antibacterial activity determination}

The antibacterial activity was determined by agar diffusion test and the minimum inhibitory concentration (MIC) by serial dilution assay according to the Clinical and Laboratory standards Institute guidelines (CLSI, 2012). Staphylococcus aureus ATCC 43300, Escherichia coli ATCC 25922 , Micrococcus luteus ATCC 10240, and Bacillus subtilis ATCC 6633, seeded on LB agar plates $(0.5 \%$ tryptone, $0.5 \%$ yeast extract, $1 \% \mathrm{NaCl}, 1.8 \%$ agar) were used as a test bacterial strains.

In disk diffusion assay $0.5,1$ and $1.5 \mathrm{mg} /$ disc of plant crude extract were used, while $2 \mathrm{mg} /$ $\mathrm{ml}$ of the plant extract and $10 \mu \mathrm{g} / \mathrm{ml}$ positive controls (penicillin G) were used as initial concentrations in serial dilution assay.

HPLC system and chromatographic conditions

The HPLC is a Waters Alliance (e2695 separations module), equipped with 2998 Photo diode Array detector (PDA). Data acquisition and control were carried out using Empower 3 chromatography data software (Waters, Germany). 
The HPLC analytical experiments of the crude extracts of the three aerial samples were run on ODS column of Waters (XBridge, 4.6 ID x 150 $\mathrm{mm}, 5 \mu \mathrm{m}$ ) with guard column of Xbridge ODS, $20 \mathrm{~mm} \times 4.6 \mathrm{~mm}$ ID, $5 \mu \mathrm{m}$. The mobile phase is a mixture of acetic acid in water $(0.5 \%)$ (solvent $A$ ) and acetonitrile (solvent $\mathrm{B}$ ) ran in a linear gradient mode. $100 \%$ (solvent $A$ ) descended to $70 \%$ (solvent A) in 40 minutes. Then to $40 \%$ (solvent $A$ ) in $20 \mathrm{~min}$. and finally to $10 \%$ (solvent $\mathrm{A}$ ) in $2 \mathrm{~min}$. and stayed there for $6 \mathrm{~min}$. and then back to the initial conditions in 2 minutes. The HPLC system was equilibrated for $7 \mathrm{~min}$. with the initial acidic water mobile phase (solvent $A$ ) before injecting next sample. All the samples were filtered with a $0.45 \mu \mathrm{m}$ PTFE filter. The PDA wavelengths range was from $210-500 \mathrm{~nm}$. The flow rate was $1 \mathrm{ml} / \mathrm{min}$. Injection volume was $20 \mu \mathrm{l}$ and the column temperature was set at $25^{\circ} \mathrm{C}$.

\section{RESULTS AND DISCUSSIONS}

\section{HPLC-PDA profiles of the extracts}

Figure 1 shows the chromatogram of the crude extract of Salvia spinosa L. (Lamiaceae) at $328 \mathrm{~nm}$. This wavelength was selected because the main peaks (eluted at $29.9 \mathrm{~min}$.) showed a maximum absorption at this wavelength. As shown in Fig. 1, about 22 minor compounds were seen, of which only one compound showed major dominance indicating flavonoids abundance ${ }^{23}$. The eluted compounds were detected in the range of 16-67 min. indicating polar and nonpolar compounds combination. The UV-Vis ranges of these compounds were in the range of 227-232 nm, and 235-275, and 297-347 nm. These compounds are not part of the standards injected as per their retention and UV-Vis spectra tell.

Figure 2 shows chromatogram of the crude extract of Salvia verbenace L. (Lamiaceae) at $328 \mathrm{~nm}$. As it is clear from this Figure, similar compounds were detected as in Fig. 1 (for Salvia spinosa L) with the 29.9 min. eluted peak is the major compound with its maximum wavelength of $328 \mathrm{~nm}$ indicating flavonoids abundance ${ }^{23-25}$. The similarity in the chromatograms of the two plant extracts indicates that these two plants have similar secondary metabolite profile as they have the same family.

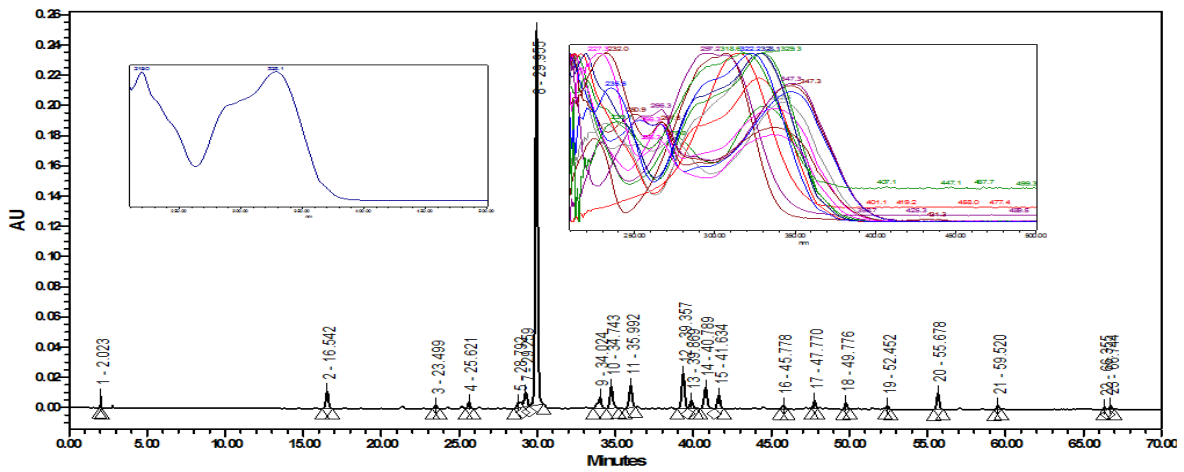

Fig. 1. HPLC-PDA chromatogram of crude extract of Salvia spinosa L. (Lamiaceae) at $328 \mathrm{~nm}$, their overlaid UV-Vis spectra (right corner of the chromatogram) and the UV-Vis spectrum of the major peak eluted at 29.9 minutes (left side to the major peak)

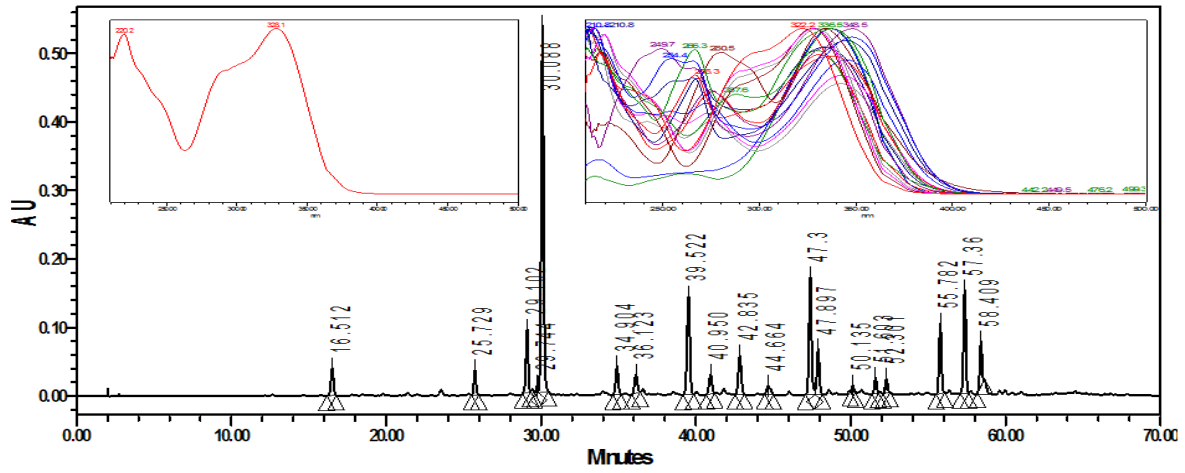

Fig. 2. HPLC-PDA chromatogram of crude extract of Salvia verbenace L. (Lamiaceae) at $328 \mathrm{~nm}$,their overlaid UV-Vis spectra (right corner of the chromatogram) and the UV-Vis spectrum of the major peak eluted at 29.9 minutes (left side to the major peak) 
Figure 3 shows chromatogram of the crude extract of Ononis natrix L. (Fabacae) at $350 \mathrm{~nm}$. This wavelength was selected because the main peaks showed a maximum absorption close to it. As it is clear from this Figure, about 22 compounds were seen of which the 44 min. eluted peak is the major compound with its maximum wavelength at 350 $\mathrm{nm}$ indicating flavonoids abundance (23-25). Fig. 4 shows chromatogram of the same extract at $260 \mathrm{~nm}$ with new compounds detected and with the major peak at $60.2 \mathrm{~min}$. and a group of peaks eluted at retention times of 61-67 min. indicating the presence of nonpolar compounds.
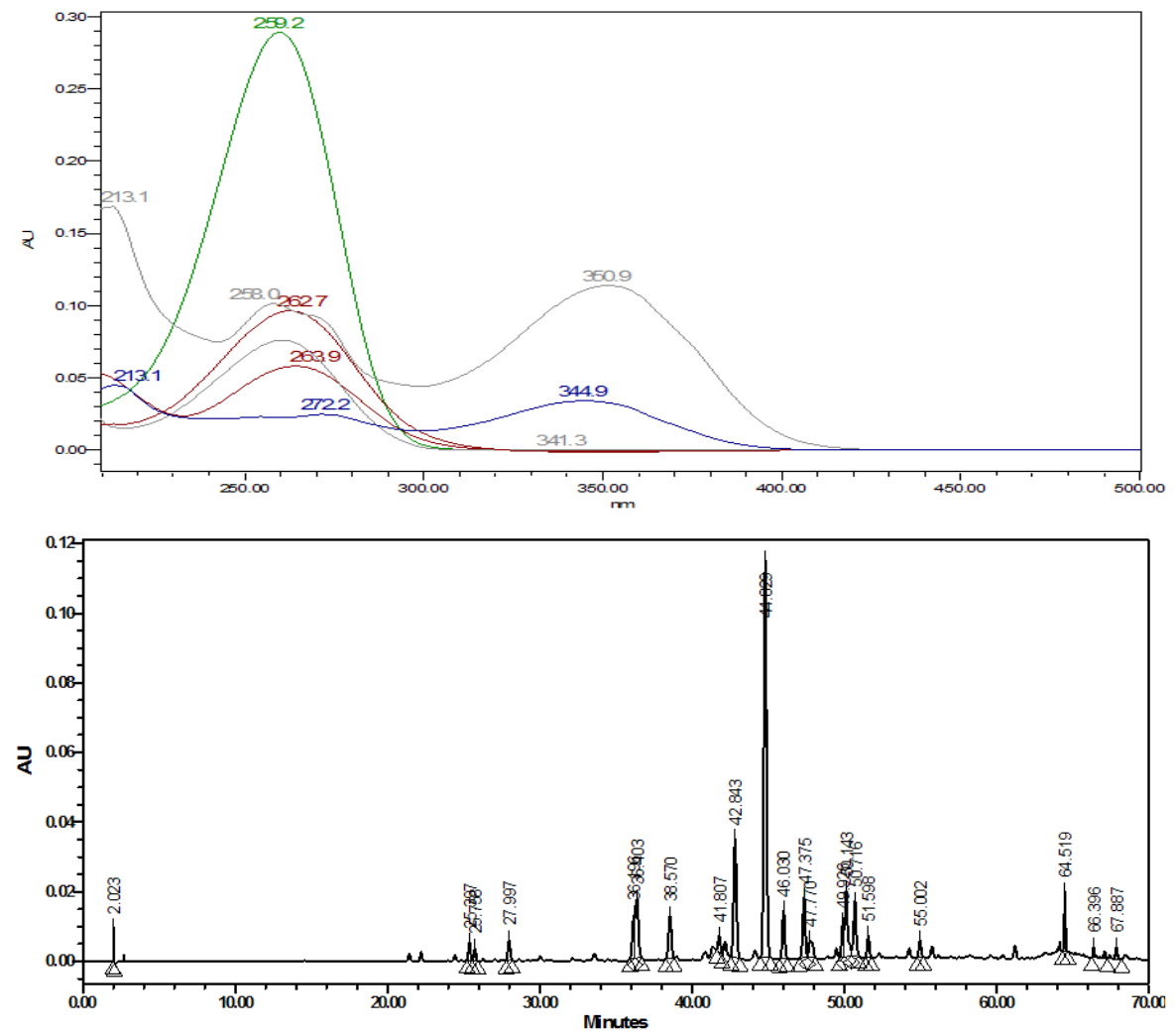

Fig. 3. HPLC-PDA chromatogram of crude extract of Ononis natrix L. (Fabacae) at $350 \mathrm{~nm}$, their overlaid UV-Vis spectra (right corner of the chromatogram).

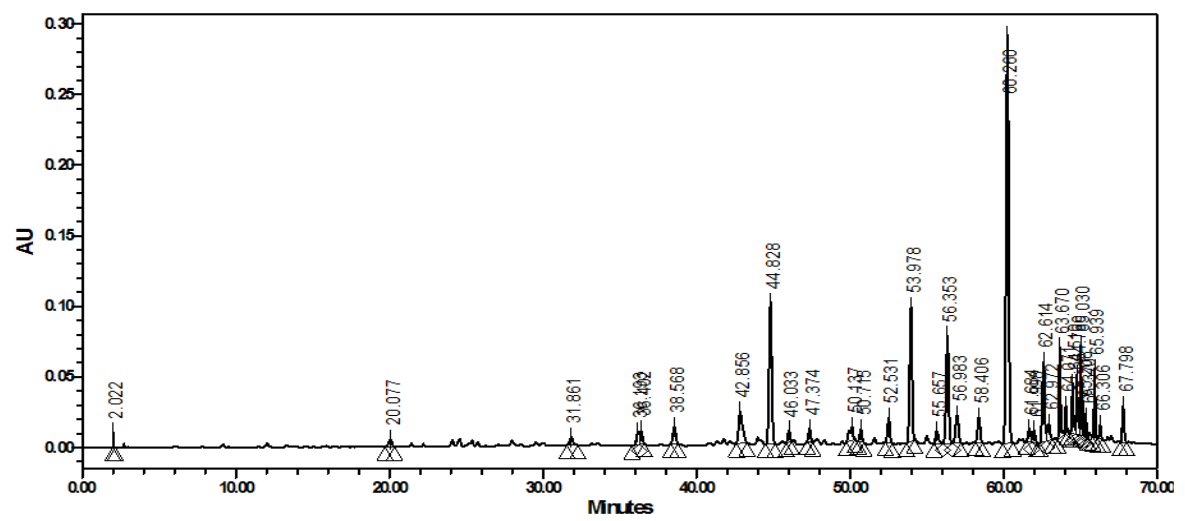

Fig. 4. HPLC-PDA chromatogram of crude extract of Ononis natrix L. (Fabacae) at $260 \mathrm{~nm}$

\section{Antibacterial activity of the plant extracts}

The antibacterial activity of plant extracts is shown in Table 2. O. natrix and S. verbenace crude extracts exhibited a moderate antibacterial activity against $B$. subtilis and E.coli with MIC $(0.5-1 \mathrm{mg} /$ $\mathrm{ml})$. However, none of the tested plants affected the 
growth of $S$. aureus as different mechanisms of drug resistance in $S$. aureus are known ${ }^{26}$ which may be the profound basis of its resistance to applied plant extracts.

Although both Salvias species showed the same chromatograms indicating presence of similar secondary compounds, however, these metabolites were more intensified in $S$. verbenace which may lead to its exhibited antibacterial activity. Moreover, presence of nonpolar compounds detected in the $O$. natrix chromatogram in addition to the abundance of flavonoids gave it the superior potency over other tested plant extracts especially as they may easily overcome the cell wall barrier.

In fact, different Salvia species (S. officinalis,
S. triloba, S. spinosa and S. dominica) were reported to exhibit antibacterial activates ${ }^{27-28}$. However, $S$. verbenace was not thoroughly included in studies on Jordanian medicinal plants with a recent verified antibacterial activity against Gram positive $B$. subtilis and $B$. brevis ${ }^{29}$. Moreover, few studies had reported that $O$. natrix exhibited antibacterial activities at concentrations over $1 \mathrm{mg} / \mathrm{disc}^{17}$.

The correlation between flavonoids and antibacterial activities has been reported previously. In fact, the lipophilic properties of these substances enable them to deteriorate the cell wall and cell membrane of microorganisms, to inhibit nucleic acid synthesis, structural and enzymatic proteins ${ }^{5}$. They have the capacity to form complexes with extracellular and soluble proteins and with the cell wall ${ }^{30}$.

Table 2: Antibacterial activity of crude extract of different plants against susceptible bacterial strains in agar diffusion test

\begin{tabular}{lccc}
\hline Plant name & & $\begin{array}{c}\text { Inhibition zone }(\mathrm{mm} \pm \mathrm{SDa}) \\
1 / 1.5(\mathrm{mg} / \mathrm{disc})\end{array}$ & \\
& B. subtilis & E. coli & S. aureus \\
\hline O. natrix & $7.3 \pm 0.6 / 10.3 \pm 0.6$ & $8.3 \pm 1.2 / 9.7 \pm 0.6$ & $\mathrm{NA}$ \\
S. spinose & $\mathrm{NA}$ & $\mathrm{NA}$ & $\mathrm{NA}$ \\
S. verbenace & $7.7 \pm 0.6 / 11.7 \pm 0.6$ & $7.7 \pm 1.2 / 8.7 \pm 0.6$ & $\mathrm{NA}$ \\
\hline
\end{tabular}

a) Standard deviation / NA: Inactive

Table 3: Minimal inhibitory concentration of plants crude extract against susceptible bacteria

\begin{tabular}{lccc}
\hline Plant name & \multicolumn{3}{c}{ MIC $(\mathrm{mg} / \mathrm{ml})$} \\
& B. subtilis & E. coli & S. aureus \\
\hline O. natrix & $0.5 \mathrm{~s}$ & $0.5 \mathrm{~s}$ & $>2$ \\
S. verbenace & $0.5 \mathrm{c}$ & $1 \mathrm{~s}$ & $>2$ \\
Penicillin G & $0.00016 \mathrm{c}$ & $>0.01$ & $0.00032 \mathrm{c}$ \\
\hline
\end{tabular}

c: bacteriocidal / s: bacteriostatic

\section{CONCLUSION}

In this study the identified plant extracts had considerable in vitro activity against $B$. subtilis and E. coli. Considering that these plants are edible and are traditionally used as folk medicine for treatment of a number of bacterial based diseases. Their bioactivity is quite significant and could present alternative treatments for many infections.

\section{ACKNOWLEDGMENT}

Authors wish to acknowledge Mutah University and Al-Quds University for providing facilities, and encouragement.

\section{REFERENCES}

1. Hassawi, D.; Kharma, A. Antimicrobial activity of some medicinal plants against Candida albicans. J. Biol. Sci., 2006, 6, 109-114.

2. Nenaah, G. Antibacterial and antifungal activities of (beta)-carboline alkaloids of Peganum harmala $(L)$ seeds and their combination effects. Fitoterapia., 2010. 81, 779-782.
3. Al-Mazaideh, G. M.; Abu-Sbeih, K. A.;, Khalil S. M., Computational Calculations of Chitosan Fragments as Corrosion Inhibitors of Metals. J. Chem., Biolo., Phy. Sci., 2017, 7(2), 398-409.

4. Al-Mazaideh, G. M.; Carbohydrates as Green Corrosion Inhibitors of Cooper: Ab initio Study, Jord. J. Chem., 2017, 12(4),189-200. 
5. Cioch, M.; Satora, P.; Skotniczny, M; SemikSzczurak, D., Tarko, T. Characterisation of Antimicrobial Properties of Extracts of Selected Medicinal Plants. Pol. J. Microbial., 2017, 66, 463-472.

6. Balunas, M.J; Kinghorn A.D. Drug discovery from medicinal plants. Life Sci., 2005, 78, 431-441.

7. Hudaib, M.; Mohammad, M.; Bustanji, Y., Tayyem, R.; Yousef, M.; Abuirjei, M.; Aburjai T. Ethnopharmacological survey of medicinal plants in Jordan, Mujib Nature Reserve and surrounding area. J. Ethnopharmacol., 2008. 120, 63-71.

8. Oran, S.A., Al-Eisawi, D.M. Checklist of medicinal plants in Jordan. Dirasat., 1998, 25, 84-112.

9. Al-Momani, W., Abu-Basha, E., Janakat, S., Nicholas, R., Ayling, R. In vitro antimycoplasmal activity of six Jordanian medicinal plants against three Mycoplasma species. Trop Anim Health Prod., 2007, 39, 515-519.

10. Aburjai, T., Darwish, R.M., Al-Khalil, S., Mahafzah, A. and Al-Abbadi A. Screening of antibiotic resistant inhibitors from local plant materials against two different strains of Pseudomonas aeruginosa. J. Ethnopharmacol., 2001, 76, 39-44.

11. Tawaha, K., Alali, F.Q., Gharaibeh, M., Mohammad, M. and El-Elimat, T. Antioxidant activity and total phenolic content of selected Jordanian plant species. Food Chem., 2007. 104, 1372-1378.

12. Darwish, R.M., T. Aburjai. Antimicrobial activity of some medicinal plants against different Candida species. Jord. J. Pharm. Sci., 2011, 4, 70-80.

13. Darwish, M., Al-Ramamneh, E., Salamon, I., Abu-Dieyeh, Z., Al Nawaiseh, M. and Al-Bdour, T. Determination of essential oil bioactive components and rosmarinic acid of Salvia officinalis cultivated under different intra-row spacing. Not. Sci. Bio., 2013, 5, 198-203.

14. Flamini, G., Cioni, P.L., Morelli, I., Bader, A. Essential oils of the aerial parts of three Salvia species from Jordan: Salvia lanigera, S. spinosa and S. syriaca. Food Chem., 2007, 100, 732-735.

15. Abu-Irmaileh, B.E., Afifi, F. Herbal medicine in Jordan with special emphasis on commonly used herbs. J. Ethnopharmacol., 2003, 89, 193-197.
16. Aburjai, T., Hudaib, M., Tayyema, R., Yousef, M., Qishawi, M. Ethnopharmacological survey of medicinal herbs in Jordan, the Ajloun Heights region. J. Ethnopharmacol., 2007, 110, 294-304.

17. Al-Bakri, A.G., Afifi F. Evaluation of antimicrobial activity of selected plant extracts by rapid XTT colorimetry and bacterial enumeration. $J$. Microbiol. Methods., 2007, 68, 19-25.

18. Al-Qudah, M. A., Al-Jaber, H. I., Abu Zarga, M. H., Abu Orabi, S. T., Flavonoid and phenolic compounds from Salvia palaestina L. growing wild in Jordan and their antioxidant activities. Phytochemistry., 2014, 99, 115-120.

19. Fu, L., Xu, B.T., Xu, X.R., Qin, X.S., Gan, R.Y., Li, H.B. Antioxidant capacities and total phenolic contents of 56 wild fruits from south China. Molecules., 2010, 15, 8602-8617.

20. Cross C. E. Oxygen radicals and human diseases. Ann Intern Med., 1987. 107, 526-45.

21. Marx J. L. Oxygen free radicals linked to many diseases. Science., 1987, 235, 529-31.

22. Rustaiyan, Abdolhossein, Katayoun Javidnia, Mohammad Hossein Farjam, Mohammad Kazem Mohammadi, and Nima Mohammadi. "Total Phenols, Antioxidant Potential and Antimicrobial Activity of the Methanolic Extracts of Ephedra Laristanica., 2011 5(24).1996-0875: 5713-717.

23. Al-Rimawi, F., Abu-Lafi, S., Abbadi J., Alamarneh, A., Sawahreh, R., Odeh, I. Analysis of phenolic and flavonoids of wild Fphedra alata plant extracts by LC/PDA and LC/MS and their antioxidant activity, Afr J Tradit Complement Altern Med., 2017, 14(2), 130-141.

24. Arora, S. Itankar, P. Extraction, isolation and identification of flavonoid from Chenopodium album aerial parts. Journal of Traditional and Complementary Medicine, 2018 https://doi. org/10.1016/j.jtcme., 2017, 10, 002.

25. Kurioka, A., Masayoshi Yamazaki, M. Purification and Identification of Flavonoids from the Yellow Green Cocoon Shell (Sasamayu) of the Silkworm, Bombyx mori , Bioscience, Biotechnology, and Biochemistry, 2002, 66(6), 1396-1399. 
26. Gordon, R., Lowy, F. Pathogenesis of methicillinresistant Staphylococcus aureus infection. Clin. Infect. Dis., 2008, 46, 350-359.

27. Canzoneri, M., Bruno, M., Rosselli, S., Russo, A., Cardile, V., Formisano, C., Rigano, D., Senatore, F. Chemical composition and biological activity of Salvia verbenaca essential oil. Nat. Prod. Commun., 2011, 6, 1023-1026.

28. Al-Rehaily, A.J., Ahmad, M., Yousaf, M., Iqrar Khan, S., Mustafa, J., Tekwani, B.L., Jacob, M., Al-Yahya, M.A., Al-Said, M.S., Zhao, J., Ahmad Khan, I. Bioactive chemical constituents of Ononis natrix. J. Chem. Soc. Pak., 2014, 36, 1114-1121.

29. Al-Zereini, W. Ononis natrix and Salvia verbenaca: two Jordanian medicinal plants with cytotoxic and antibacterial activities. $J$. Herbs Spices Med. Plants., 2016, 1, 18-25.

30. Araujo, M.G., Hilario, F., Nogueira, L.G., Vilegas, W., dos Santos, L.C., Bauab, Y.M. Chemical constituents of the methanolic extract of leaves of Leiothrix spiralis Ruhland and their antimicrobial activity. Molecules., 2011, 16, 10479-10490. 